\title{
The Zoolander Effect: Equivalent Models in Ecology and Evolution
}

\author{
Ronald Bassar ${ }^{1}$, Tim Coulson ${ }^{2}$, Joseph Travis ${ }^{3}$, and David Reznick ${ }^{4}$ \\ ${ }^{1}$ Williams college \\ ${ }^{2}$ Oxford \\ ${ }^{3}$ Florida State University \\ ${ }^{4}$ University of California-Riverside
}

November 27, 2020

\begin{abstract}
In the 2001 film Zoolander, the lead character, played by Ben Stiller, ditches his old "Blue Steel" look and develops an exciting new 'Magnum" look that the fashion industry enthusiastically embraces. The evil mastermind, Mr Mugato, played by Will Farrell, exclaims "The man has only one look, for Christ's sake! ... They're the same face! Doesn't anybody notice this? I feel like I'm taking crazy pills!" We argue here that eco-evolution is the "Magnum" of biology: it is fashionable, lots of people love it, but it is not new. We also argue that, like the "Blue Steel" look in the 2016 sequel, Zoolander 2, eco-evolution is being seen where it does not belong.
\end{abstract}

\section{Hosted file}

The Zoolander Effect 2020-11-25.pdf available at https://authorea.com/users/379437/articles/ 495641-the-zoolander-effect-equivalent-models-in-ecology-and-evolution 